\title{
Networked participatory online learning design and challenges for academic integrity in higher education
}

\author{
Judy O'Connell
}

\begin{tabular}{l}
\hline Correspondence: \\
juoconnell@csu.edu.au \\
Division of Student Learning \\
u!magine Digital Learning \\
Innovation Laboratory, Charles Sturt \\
University, Wagga Wagga, Australia
\end{tabular}

Springer Open

\begin{abstract}
A new multi-disciplinary degree program in education and information studies was developed to uniquely facilitate educators' capacity to be responsive to the demands of a digitally connected world. Charles Sturt University's Master of Education (Knowledge Networks and Digital Innovation) aims to develop agile leaders in new cultures of digital formal and informal learning. The co-construction of knowledge through interpersonal discourse creates a pedagogical tension between a focus on knowledge-based instruction and outcomes, and on praxis-based instruction. This digital context draws attention to academic integrity issues in online learning environments. Through the new subject Game-Based Learning, students engaged in theory, practice, trends in game designs and immersive aspects of game, utilizing the technology and pedagogical affordances of a range of online tools. The subject builds on the keystone subject and incorporates reflective participation and a culture of participatory learning through integration of social media, social scholarship and open sharing of ideas, resources and experiences online within the broader education community. Subject engagement and assessment design incorporated academic integrity strategies, and needed individual and group collaboration to be fully integrated into the learning experience of the students, thus modeling practices relevant to the student's own processional practices. This paper also considers the contribution of global connectedness to the success of the pedagogic processes used for embedding academic integrity through social scholarship into the curriculum and learning experiences.
\end{abstract}

Keywords: Participatory culture, Game-based learning, Academic integrity, Online learning, Information ecology

\section{Background}

Distance education and distance learning, once undertaken by one-to-one correspondence between learners and teachers has been radically transformed into online learning, or e-learning, through the use of learning management systems and other web based or digital tools. Now this type of education is characterized not so much by 'distance' as by the mode of 'electronic' or ' $e$ ' learning environments that is internet or web-based, and provides ongoing challenges for the researcher investigating professional contribution (i.e. teaching or educating') in higher education (Thompson 2007. p. 11) and the facets of academic integrity for students learning in internet and online environments (Sutherland-Smith 2008).

(C) The Author(s). 2016 Open Access This article is distributed under the terms of the Creative Commons Attribution 4.0 International License (http://creativecommons.org/licenses/by/4.0/), which permits unrestricted use, distribution, and reproduction in any medium, provided you give appropriate credit to the original author(s) and the source, provide a link to the Creative Commons license, and indicate if changes were made. 


\section{Introduction}

Distance education has evolved through many technologies, in tandem with the affordances these technologies provided, and each mode or 'generation' has required that distance educators and students be skilled and informed to select the best mix(es) of both pedagogy and technology (Anderson and Dron 2011). The current generation of academic degree programs which are delivered fully online (rather than face-to-face) through the use of information and communication technology (ICT) are doing more than simply delivering content through asynchronous distance education modes. Rather, there has been a strong move to creating pedagogically enriched learning design within technology-rich contexts to support and improve learning experiences (Ally 2004; Kim and Bonk 2006; Siragusa et al. 2007; Beetham and Sharpe 2013).

A growing number of studies have considered learning and teaching activities in online learning environments in higher education, examining such aspects as multimedia resources, blended and online new technologies, and the many ways in which online learning and teaching are now being conceptualised and embraced to engage students in learning and promote positive online learning experiences (Boling et al. 2012; Cho et al. 2015; Lang and Lemon 2014; McLoughlin and Lee 2011). In practical terms when communication online becomes more relational, socialized and expressive, individuals are required to master an emergent, articulated repertoire of communicative competencies that mixes interpersonal and group process fluencies to make linkages and correspondences through a repertoire of competencies inextricably social and technological (Lievrouw 2011, p. 626). In this way new communities of inquiry are formed around shared interest, activity and educational experiences (Garrison et al. 1999; Shea and Bidjerano 2010), facilitated by the web as a platform for content creation and collaboration by multiple recipients (Franklin et al. 2007).

Current online information environments and associated transactions are considered an important 'information ecosystem' (Haythornthwaite and Andrews 2011) influencing and shaping professional engagement and digital scholarship in communities of learning in the higher education sector (Lee et al. 2008). John Seeley Brown (1999) used an 'ecology' metaphor to describe the emerging technology landscape as "an open system, dynamic and interdependent, drivers, partially self-organizing, and adaptive (p.3). Thomas and Brown (2011), also explored what they described as a new 'culture of learning' where information technology has become a participatory medium, giving rise to an environment that is constantly being changed and reshaped by the participation within information spaces. They argued that traditional approaches to learning are no longer capable of coping with this constantly changing world. The information environment is a technology environment, which demands adaptation. As information is also a networked resource, "information absorption is a cultural and social process of engaging with the constantly changing world around us" (Thomas and Brown 2011 p. 47).

\section{Information ecology at the heart of academic integrity}

In other words, our digital information ecology is a remix of different forms of technology, devices, data repositories, information retrieval, information sharing, networks and communication. New technological tools are expanding and continually altering the ways students, or educators can interact with the world. The implications for education that stem from new means for accessing information, communicating with others, and participating 
in a community needs a new brand of professional competences to thrive within the changing environment. Haste (2009) recognised the co-construction of knowledge through interpersonal discourse and the tension within pedagogy between a focus on knowledgebased instruction and outcomes, and on praxis-based instruction. "While most pedagogy, of course, recognises the interaction of both in good practice, there is nevertheless an underlying epistemological gap; knowledge-based models are implicitly more 'top down' and praxis-based more 'bottom up'. 'Knowledge' implies that the route to understanding is in the structured transmission of information. 'Praxis' implies a necessary interaction with materials, actions or other persons as a route to understanding” (Haste 2009 p. 213).

While technology is changing the information environment (including information places and spaces), the transactional nature of information interactions and knowledge flow underpins learning. Information can comprise both physical and virtual parts for operation and interaction. A major challenge for education is to enable and facilitate the generation of new knowledge via an appropriate information environment, to facilitate integration of new concepts within each person's existing knowledge structure. This is described as an 'information ecology'.

"Information ecology examines the contexts of information behaviour by analogy with ecological habitats and niches, identifying behaviours in biological terms such as 'foraging"' (Bawden and Robinson 2012 p.199). In this context of adaptive and responsive co-construction of knowledge, curriculum and subject delivery can be reshaped and reconstructed in a dynamic manner in response to changing environmental conditions or the personal professional needs of students. A digital information ecology provides the opportunity to work with information in the construction of knowledge in more dynamic ways, connecting learning experiences across the contexts of location, time, devices and platforms.

This same digital information ecology has also extended the disciplinary and pedagogic challenges relevant to learning design and the broader institutional context of responsibility for academic integrity. While it is understood that learning and teaching requires engagement with the relevant knowledge, skills, and values pertinent to the discovery and dissemination of new knowledge (Turner and Beemsterboer 2003) the connections to how and when this process relates to either embedding or fostering academic integrity is less clear. In the literature review undertaken by Macfarlane et al. (2014) the predominant focus emerging in the literature was on investigating and illustrating a perceived lack of absence of academic integrity, and in this context identified that there is a pressing need for greater understanding of academic integrity across all practice elements, including teaching. The current proactive ethos towards academic integrity is influenced not only by policy actions, such as syllabi and course outlines acknowledgement of academic integrity, ethical guidelines or codes of conduct, but also by the very capacity of academics to teach and/or influence the students' awareness and acceptance of academic integrity standards (Löfström et al. 2015).

This information ecology nurtures and validates a pedagogic process that involves the creation of assessments and environments for knowledge building to enhance collaborative efforts to create and continually improve ideas. This type of approach to knowledge building "exploits the potential of collaborative knowledge work by situating ideas in a communal workspace where others can criticize or contribute to their improvement" (Scardamalia et al. 2012 p. 238). Learners in online 
environments do not learn at exactly the same time and the focus on individualised learning is highlighted, even emphasizing the time constraints and restrictions in modes of collaboration (Zheng and Dahl 2010). While asynchronous and synchronous communication is characterized by different discourse features (Romiszowski and Mason 2004), it is recognised that two-way communication remains a critical feature of the e-learning educational process, as well as being a way of engaging the learners within the e-learning environment (Desai et al. 2008 p. 328). So while technology has not changed the fundamental capacity for learning, ICT has changed how ideas and practices are established, communicated and maintained when considered in the context of the established educational discourse. Our work as educators has to centre on helping to meet future learning needs in courses/programs by fostering a culture of enquiry within a sustainable learning ecology that is shaped by the ubiquity of information, globally responsive pedagogical practices, academic integrity, and driven by collaboration and informal learning in multiple access points and through multiple mediums.

The phenomenon of academic dishonesty has attracted much interest over the years and the challenges and strategies for maintaining quality assurance is often addressed by policies, coupled with an investigation of new strategies for assessing the iGeneration' (Baggio and Beldarrain 2011). What is required is a pathway forward to ensure that academic integrity in online learning programs and $21^{\text {st }}$ century learning environments responds to open learning and collaborative practices, in pedagogy and professional skill development of students.

The study by Prescott (2016) corroborates this emphasis on choice and collaboration as providing a valuable framework for helping students build defences against inadvertent plagiarism in their study behaviours. Both project premise and teaching aims coupled with good academic practice in collaborative writing activities demonstrated how online work in wikis could make writing 'visible' and create self-awareness with more effective self-monitoring with engaging resources.

\section{Case description}

The Master of Education (Knowledge Networks \& Digital Innovation) commenced at Charles Sturt University in 2014 and requires completion of sixty-four (64) points comprising two (2) core subjects and six (6) elective eight (8) point subjects, to meet the Australian Qualifications Framework standards for a Masters degree by Coursework (Council 2013). It is being delivered fully in online distance education mode, lead by the Courses (Program) Director and the education discipline team in the School of Information Studies, drawing on specialist adjunct staff associated with the School.

The program is designed to respond to the following:

- Literature and literacy experiences in digital environments, including children's and young adult literature, e-book systems, management and development;

- Information organisation in digital environments, information retrieval, content curation with the aid of mobile devices, online platforms and cloud based storage services;

- Concepts and practices for curriculum integration of social media tools, services and platforms; 
- Information practices, with an emphasis on information fluency, critical inquiry and design thinking;

- Digital citizenship essentials, including legal and ethical behaviour and open learning approaches;

- ICT integration and innovation, demonstrating a technology infusion with mobile learning, tablets and devices for information rich learning experiences; and

- Creative and intellectual leadership in a global environment.

The program is grounded in cross-disciplinary studies in education and information, allowing students to gain an advanced and integrated understanding of an important body of knowledge related to information and knowledge transactions in online knowledge networks, built on processes and interactions for innovative education practice. It aims to encapsulate a participatory information ecology that is a co-construction of knowledge through interpersonal discourse and the tension within pedagogy between a focus on knowledge-based instruction and outcomes, and on praxis-based instruction, which is both creative and dialogic. The learning processes depend more on the coordination among all the interactions and activities that take place in different spaces of the learners' lives (personal, home, and workplace) rather than only on interactions and activities developed in the spaces of formal learning within Interact2 (Blackboard) learning management system.

The academic program has also been designed to enhance personal professional networks and personal learning conversations, understanding that learning is social within Communities of Practice where learning happens through experience and practice as part of a community (Lieberman and Mace 2009). Each subject is treated as an intensive professional development program, facilitated by social interaction through forums, twitter, Adobe Connect, and Google Hangouts, helping to facilitate greater insight into generic issues (Rienties and Kinchin 2014) through the various participatory learning experiences.

The learning framework for the program is established in the keystone subject INF530 Concepts and Practices in a Digital Age, where a body of knowledge is introduced that includes a review of recent developments which are influencing learning and teaching in an increasingly digitally connected world. By examining key features and influences of global connectedness, information organisation, communication and participatory cultures of learning, students are provided with the opportunity to reflect on their professional practice in a networked learning community, and engage in dialogue to develop an authentic understanding of concepts and practices for learning and teaching in digital environments (O'Connell 2014). Through this questioning, review and reconstruction of understanding, the subject frames the challenges of learning in digital environments and sets the context for innovation and change in professional practice. The subject is designed to provide: professional learning through authentic tasks and activities; opportunities for collaboration with peers; readings that are thought-provoking; study suggestions which encourage inquiry, reflection and analysis; and engagement with a curriculum unit/strategy to demonstrate application of new knowledge and understanding for learning and teaching practice.

This foundation subject establishes connected learning within new information environments created by the social and technological changes of the digital age. The purposeful pedagogical praxis allows: 
- Interaction with a diversity of content materials;

- Interactions within the cohort to improve learning and understanding in the formation of knowledge;

- Interaction through use of social media communication channels; and

- Interaction embedded in a multi-disciplinary information ecology.

By focusing on connectivity, communication, collaboration and convergence, the subject addresses the challenges, opportunities and emerging possibilities for learning and teaching in information-rich participatory environments. Trends in knowledge construction, participation and social networks are explored, including information futures and digital convergence. The subject introduces education informatics and the scholarship of digital teaching, and models connected learning through group discourse and collaborative inquiry in digital environments, including the reflective and participatory experiences employed throughout the course.

The first cohort of 42 students was drawn from Australian and international educators, who were in leadership positions in schools; classroom teachers and teacher librarians; e-learning leaders in schools and higher education; educational designers in higher education; program leaders in education organisations; and technology integrators in schools and higher education. The range of admissions demonstrated well the multi-disciplinary program approach Table 1 .

The ongoing admissions during 2014 and 2015 continued to attract applicants from the same cross-section of education, preparing an interesting cohort of students for the first delivery of the subject Game-Based Learning in 2015. The subject cohort in INF536 Game-based Learning was represented by the following group of students Table 2.

Table 1 First intake for MEd(KN\&Diglnnov) 2014

\begin{tabular}{lc}
\hline Role & Number \\
\hline Classroom teacher & 14 \\
Teacher librarian & 18 \\
School leadership & 3 \\
School e-learning integrators & 2 \\
Faculty education/instructional designers & 4 \\
Academic librarian & 1 \\
Total & 42 \\
\hline
\end{tabular}

Table 2 Game-based learning subject cohort 2015

\begin{tabular}{lc}
\hline Role & Number \\
\hline Classroom teacher & 10 \\
Teacher librarian & 3 \\
School leadership & 2 \\
School e-learning integrators & 4 \\
Faculty/TAFE education/instructional designers & 5 \\
Faculty/Systems engineer & 1 \\
Total & 25 \\
\hline
\end{tabular}




\section{Discussion and evaluation}

The design of assessments in participatory e-learning environments must emphasise digital flexibility and open collaboration. The ability to evaluate the validity and value of information accessed from multiple information environments is essential for scholarly $21^{\text {st }}$ learning and academic integrity. Approaches to assessment focus on participatory and digital experiences, in the context of program requirements, and include extensive use of formative activities, as part of knowledge flow and peer-to-peer learning/engagement. Social media channels are a vital part of this approach.

Many students keep an open and public record of their learning. providing an easy (and open) way to see the range of digital learning/assessment experiences alongside a record of their participatory experiences and online interactions, in keeping with the global participatory nature of the program. eg. http://thinkspace.csu.edu.au/becspink; http://thinkspace.csu.edu.au/msimkin/; http://thinkspace.csu.edu.au/andrewp/.

"In professional programmes in particular, it is useful if students keep a reflective journal, in which they record any incidents or thoughts that help them reflect on the content of the course or programme. Such reflection is basic to proper professional functioning. The reflective journal is especially useful for assessing ILOs (intended learning outcomes) in relating to the application of content knowledge, professional judgment and reflection on past decisions and problem solving with a view to improving them." (Biggs and Tang 2011, p. 261). Students are regularly required to reflect upon their practices, link their reflections to theories and communicate in writing an understanding of the connection between the reflection and theory. This encourages each student to become a proactive learner and reflective educator who is "committed to continuous improvement in practice; assumes responsibility for his or her own learning; demonstrates awareness of self, others, and the surrounding context; develops the thinking skills for effective inquiry; and takes action that aligns with new understandings" (York-Barr et al. 2006 p. 10).

Reflective thinking helps students develop a questioning attitude and new perspectives, identify areas for change and improvement, respond effectively to new challenges, and generalise and apply what they have learned from one situation to other situations (Turner et al. 2011). This experiential engagement is employed to foster creativity and initiative for new situations in connected environments for professional practice, and a capacity for confident personal autonomy and accountability in knowledge networking. This participatory approach also provides the grounding for new approaches to academic integrity. When students are watching and learning from each other, they are learning to work with an 'open education' ethos, and begin to support each other in research and thinking. By doing so, students can ensure the quality of their work, online, and through public scrutiny are also enabling a new level of academic integrity beyond scrutiny by services such as TurnitIn.

The collaborative nature of the pedagogical approach was transparent almost from the outset. The subjects all utilise new and emerging technologies (social networking, media production, content curation, innovative approaches to presentations and more), all hand in hand with traditional e-learning approaches. The effect of this was immediately highlighted by the public sharing from the Keystone subject via Twitter hashtag \#INF530. The bottom-up praxis was emphasised by a willingness of students to post a link to their assessments, via their reflective blog or relevant platform - even before the assessment was marked! After the assessments were marked, regardless of the grade level achieved, even more students willingly shared their work. A highlight for students was 


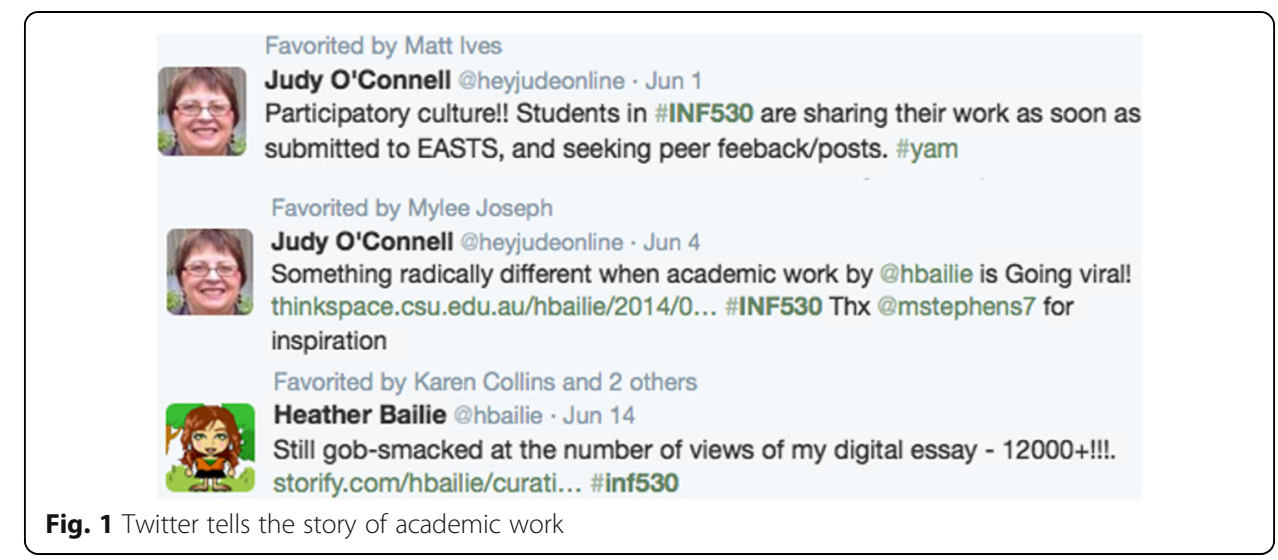

when an assessment went 'viral', being picked up by some knowledgeable people and organisations. See http://thinkspace.csu.edu.au/hbailie/2014/06/04/going-viral/ Fig. 1.

Students utilised participatory and collaborative tools and approaches throughout the keystone subject, with many learning for the first time how to engage at this level. An excerpt from final blog reflections in the first subject highlighted the transformation:

"My progression through INF530 has been a brilliant start to my journey along the Masters of Education (Knowledge Networks and Digital Innovation) path. The subject content has provided me strong foundations to build upon, and has been highly relevant to my workplace".

"INF530 has convinced me even more of the need for all teachers to become digitally literate, connected educators"

"\#INF530: Concepts and Practices for the Digital Age has left me continually thinking, questioning, reflecting on current practices causing the continual shift of opinions regarding technology and education. And this is only the tip of the iceberg."

"\#INF530 has been invigorating, exciting, lots of hard work, overwhelming at times, but above all fun. I have loved connecting with the cohort, it's been amazing. People have said to me "isn't online study very impersonal and isolating" but I couldn't disagree more. I feel infinitely more connected with my classmates than I ever did while studying in the traditional way."

Students are therefore immersed in a participatory learning experience that not only maintains and promotes a high calibre of pedagogical knowledge encounters, but also frames a new model for promoting academic integrity in online environments through embedding open approaches from learning and assessment from the outset. This is in direct contrast to assessment practices that sit behind the 'walled garden', and do not connect directly with the global education experiences of the students.

\section{Game-based learning}

The subject, INF536 Game-Based Learning, was completed for the first time in the Session One (Autumn) of 2015. As a new subject, this provided another opportunity to embed the 
new approaches being used to promote academic integrity within the participatory experiences of the subject, and demonstrate how to respond to the challenges of quality assurance for higher education in participatory frameworks and open approaches to education.

The subject is designed as an introduction to understanding the potential role of games and gaming for learning in the digital age. Trends in game designs, cultures, genres will be explored in the context of both educational games and commercial games, which can be successfully adapted for pedagogical, curriculum and individual needs of learners. The subject introduces the principles of game design, examines research literature surrounding games and learning, and includes reflective participation in gaming culture.

The subject also covers the principles and theories of game based learning, narrative and gameplay; the characteristics of effective digital game media for a variety of uses; information behaviour and knowledge construction in game environments; pedagogical affordances of digital games; and implementing digital games into the learning environment.

Throughout their study in this subject students continue to maintain their reflective blog at Thinkspace - a platform provided for student use throughout their course/program. By providing this foundational and continuing connection point between all students and the lecturer, a vibrant community of sharing is both fostered and maintained. In this subject, the reach to the global audience was also increased by use of IFTT by the lecturer and subject team. See https://ifttt.com/

IF 'recipes' (the name of the formulae being used to gather or manage information via API services) run automatically in the background and replace manual steps in information curation and/or sharing. Two important 'recipes' allowed for the following: Fig. 2.

RSS (Rich Site Summary) is a format for delivering regularly changing web content. Many news-related sites, weblogs and other online publishers syndicate their content as an RSS Feed to whoever wants it. RSS solves a problem for those who regularly use the web making it possible to retrieve the latest content from the sites of interest. Each time a student posted to their Thinkspace blog, this post was immediately and automatically added to the lecturer's RSS reader for the subject collection which was set up at the beginning of the subject. Using an RSS reader (the reader chosen was Feedly http://feedly.com/) the lecturer could easily read new content and post responses). This new blog post, now added to the feedly account, was then 'announced' to the lecturer's Twitter feed, and made available to members of the cohort or other interested educators using the \#INF541 Twitter hashtag. This was possible through the automated IFFT 'recipe' process that was set up. Particularly good posts gained feedback from beyond the cohort Fig. 3.

However, there was another background recipe process taking place using the IFTT service Fig. 4.

Each time a student posted a tweet about anything at all on Twitter with the subject hashtag \#INF541 the information was collected in a Google Spreadsheet. This aggregation

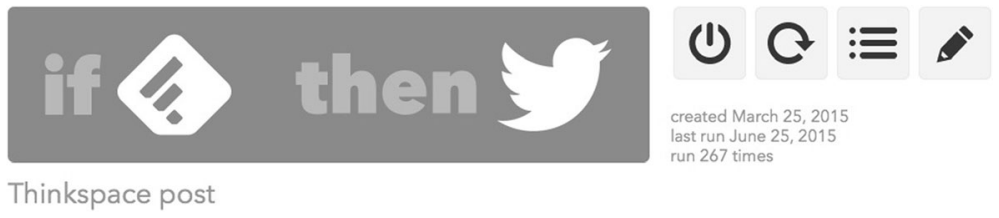

Fig. 2 Thinkspace blog post 


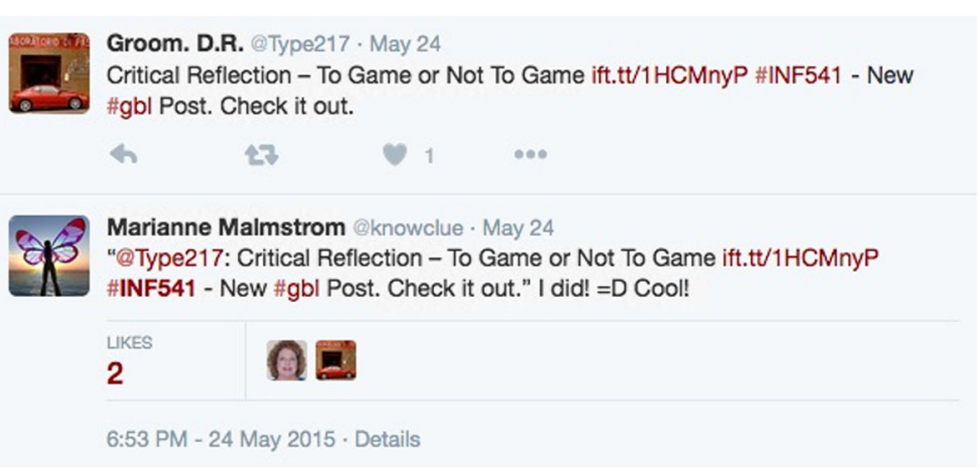

Fig. 3 \#gbl on Twitter

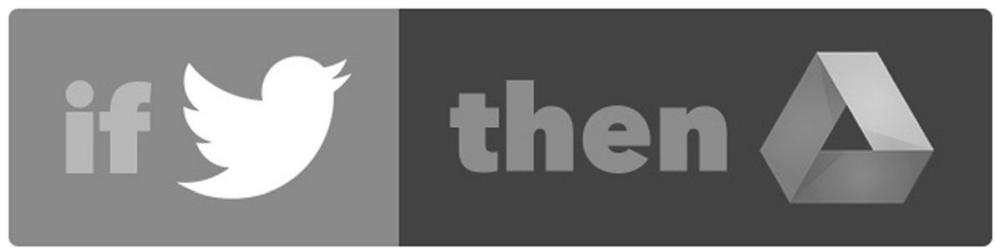

A spreadsheet of new tweets with a specific \#hashtag you pick

Fig. 4 Collecting twitter data

of data provided rich material for future analysis, particularly when tracking several cohort experiences. In total, during the subject, a total of 860 tweets were recorded!

Of course, students also engaged in focused discussion, using the Blackboard Discussion Forum tool - for in-depth group conversations on topics/questions posed during the subject learning experiences. These created equally frequent and popular in-depth discussion and conversations which demonstrated the extent and multiplicity of engagement amongst students, ranging from rapid twitter conversations to in-depth Discussions and personal reflections on Thinkspace.

This combination of collaborative, social experiences has driven very different learning experience, allowing affirmation of the formative learning experiences to be re-enforced by the formulation of assessment strategies that represent a more collaborative and open approach to formal assessment. It is in the area of formal assessments that the true value of academic integrity fostered through social media and online open experiences comes to the fore.

The extent of global influence on formative approaches to subject design were exemplified by the inclusion of a student blog post entitled 'Digital Game Based learning levels up digital literacies' http://thinkspace.csu.edu.au/anotherbyteofknowledge/digitalgame-based-learning-levels-up-digital-literacies/ in Episode 12 TIDE Today in Digital Education podcast from Dai Barnes and Doug Belshaw http://tidepodcast.org/. The blog post was described as being well referenced and an excellent starting point for anyone interested in understanding the connections between digital literacy and gamebased learning. This kind of feedback is unique and only available to students participating in open and participatory learning experiences. 
The first assessment, a critical review of three articles, provides a 'traditional' approach to assessment to ensure connection and engagement with relevant research. In a very straightforward way the assessment ask is designed to provide students with opportunities to:

- demonstrate an understanding of the features, terminology, history and taxonomy of computer-based games and gaming applications

- evaluate and critically assess the relation between play, games and learning in formal and informal settings

- discuss the relationship between games, media-literacy, information fluency and digital identity.

By retaining assessment of this nature, students have a direct connection to standard academic assessment processes, running in parallel to the participatory and formative activities via Thinkspace reflective blogging, discussion forums and Twitter engagement. However, building on all the formative and participatory experiences, the final major assessment is also a collaborative and online learning experience.

\section{Compendium in game-based learning 21C \#gbl}

Students were asked to "Prepare a chapter as your contribution to the Compendium: GameBased Leaning 21C \#gbl for an open educational resource. The compendium is designed to bring student into the open publishing environment, while also fostering academic integrity built on the collaborative and participatory experiences in this subject and throughout the course/program. Each student contributed a chapter to the digital compendium, and collaborated on the choice of topic through a proposal process managed through a purpose-built wikispace set up for that purpose. As students wrote their proposals, the peer group critiqued the proposal, provided feedback or encouragement, and together a final format/topic was chosen. The topics were not open-ended, so much as clustered around a 'provocation'.

"In this task, you will be guided to work collaboratively to choose your chapter contribution for ONE (1) of the following sections of the Compendium:

Part 1: Motivation: What reading, research, environments, and change factors are emerging that require or validate being interested and inspired to move into gamebased learning?

Part 2: Provocation: Through a case study, an environmental scan of your organisation, situational analysis, or other activity, develop and challenge readers with a perspective based on concrete settings or experiences.

Part 3: Invitation: Invite an organisation, system or workplace to meet the challenge of game-based learning.

We explained to the students that "By combining your work together in the Compendium, we can achieve the equivalent of a book on the topic available online - that provides readers with Rationale (Part 1), Examples to show what is possible (Part 2) and ways to move forward (Part 3)."

This approach was modelled on the work undertaken at Duke University, where a web journal of final projects in the Augmented Realities humanities course was published at http://sites.duke.edu/lit80s_02_f2013_augrealities/. 
Students created their own chapter on their personal course Thinkspace site, and a duplicate version was combined into the final compendium. This allowed individual promotion via Twitter and blog feeds of their work, and finally to promote the compendium publicly via Twitter as a whole piece of work, as well as sharing the pride and accomplishment of the final online product.

The compendium was published online at http://thinkspace.csu.edu.au/gblcompendium/ for the purpose of taking the subject experience beyond the 'classroom' and into the public sphere. The compendium experience was also intended to position game-based learning as the topic of open scholarly discourse, available for students, educators and practitioners alike, and where feedback and commentary is part of the participatory learning of online environments and in keeping with the flexible and learner-focused cognitive frame of \#gbl. This approach provides a substantial mechanism for embedding scholarly practice as an action of engagement in open and participatory environments, with a focus on best practice, rather than avoidance of plagiarism. The process adopted is one of apprentice scholarly writing by participating in disciplinary activities and producing scholarly writing that is acceptable to the community (Li 2007). More than just communicating the requirements of academic integrity, the compendium facilitates a leadership approach in day-to-day scholarly practice. Because trust is a reciprocal process, the role of the lecturer is to show how trust in open environments translates into practice, utilizing a framework of trust within the instructional model to promote academic integrity (Hulsart and McCarthy 2011) Fig. 5.

Despite the many advantages to publishing student work online, there where the usual questions asked by fellow academics. How do you stop them copying or plagiarizing? How do you check their work? The answers are multiple, but include the obvious point of peer critique and collaboration to choose a different topic focus for each chapter. Peer scrutiny is intense, inspirational, but also critical of content. However, by asking students

Game-Based Learning Compendium

Home About Part 1: Motivation Part 2: Provocation

Part 3: Invitation

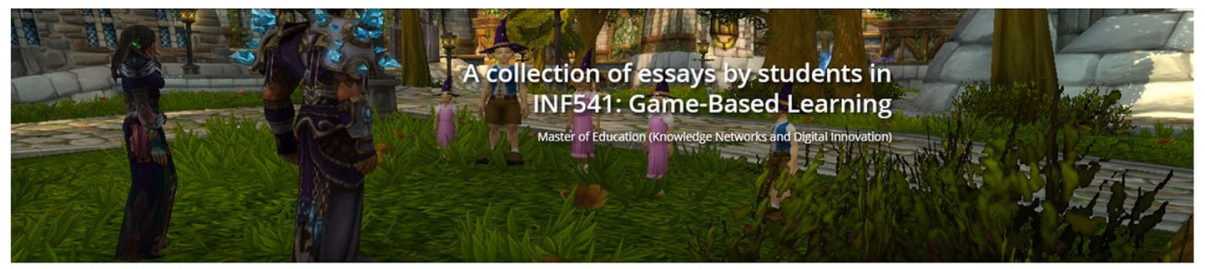

This collaboratively developed compendium is a shared open resource relevant to game-based learning. It represents the work of students whose essays may offer foundational concepts, examples, explanatory theories and guiding principles, coupled with a questioning of burning issues, to encourage a passion for game-based learning. It provides a stimulus for further \#gbl discussion.

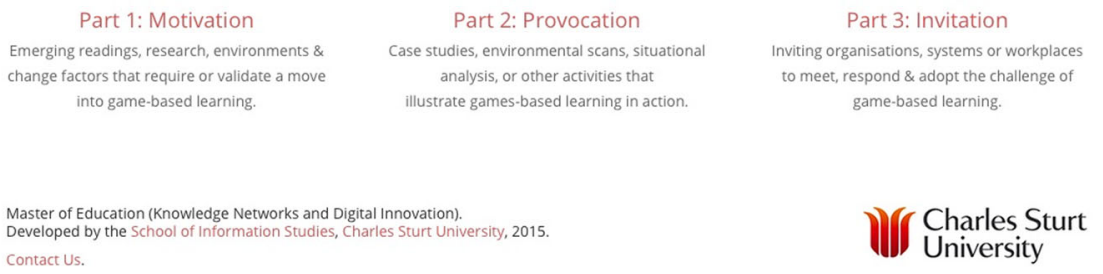

Fig. 5 GBL Compendium 

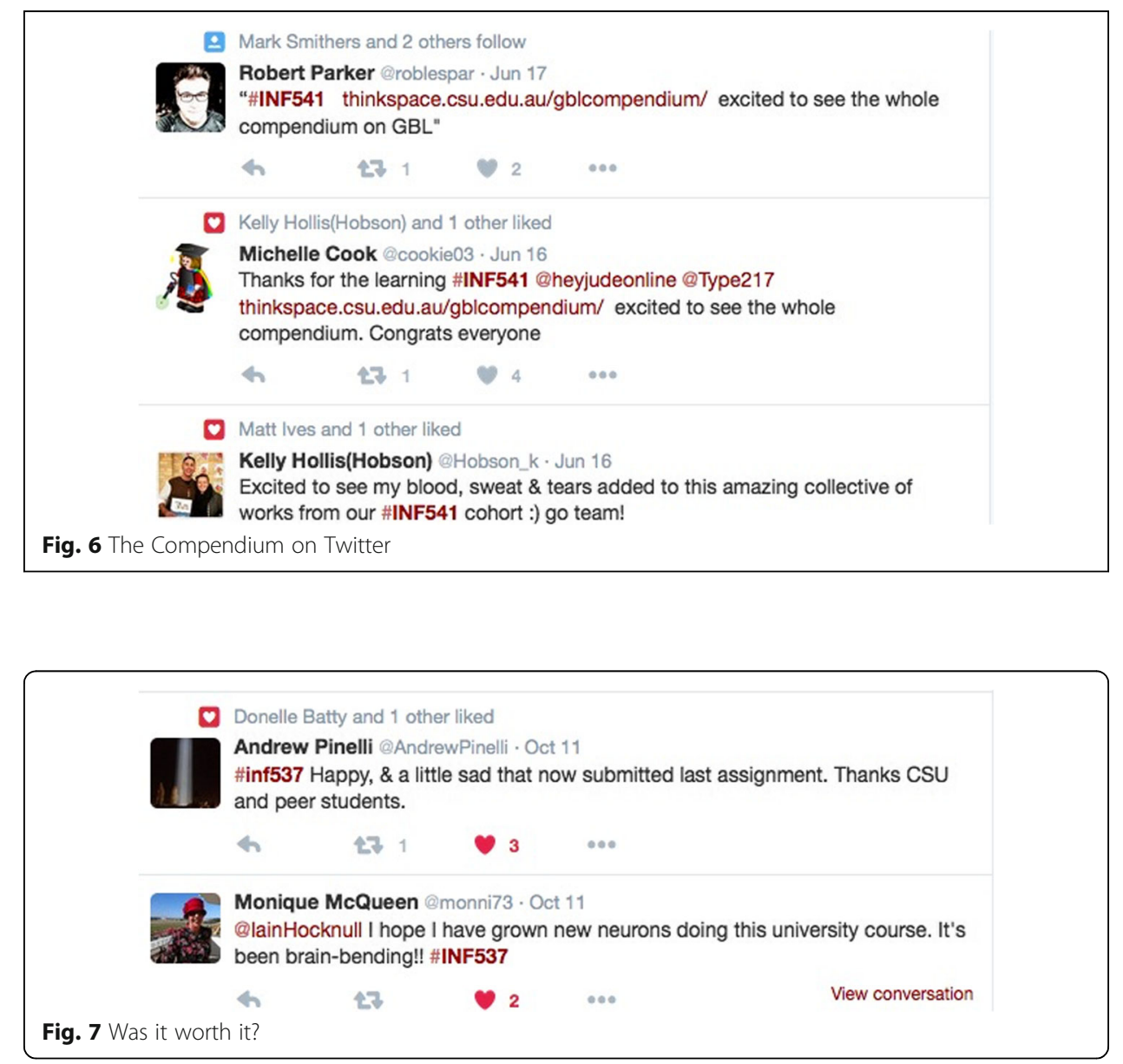

to first publish the chapter compendium as a web page on their Thinkspace blog, the lecturer was also able to use the Clearly browser plugin, which makes blog posts, articles and webpages clean and easy to read, to generate a pdf that could be submitted to Turnitin. All chapters passed Turnitin scrutiny with ease, though two compendium chapters could not be assessed due to duplication in submission.

The reaction of students, and the reach of the promotion of academic work is captured in these snippets from Twitter Fig. 6.

In all subjects that have continued, following this particular subject, students continue to publicly share their gratitude to peers and their reaction to the experiences of the program. What is of value is that this celebration of learning includes the fundamental need to foster and embed new approaches to academic integrity in keeping with $21^{\text {st }}$ participatory learning Fig. 7.

\section{Conclusion}

The creation of a multi-disciplinary program, built on a digital information ecology and student-focussed praxis, has created both a curriculum and learning approach that has facilitated understanding and knowledge construction in more dynamic ways, connecting experiences, reflective practices and online participatory experiences that epitomize a 'new culture of learning'. Both technical and pedagogical innovation should be 
hallmarks of the best learning environments we can create, and which incorporate a wide variety of pedagogical approaches, learning tools, methods and practices to support students' diverse learning modes. The collaborative nature of the course/program has been highlighted, including a significant shift to public and open sharing of formal and informal assessments. This collaborative construct, with the approach to open and visible learning has provided a transparent approach to explicitly teach academic integrity as a foundational requirement for, or enabler of, participatory learning. This multidisciplinary learning program, has resulted in a proactive, dynamic and responsive participatory learning design that embeds an approach to academic integrity which is responsive to open, participatory, socially moderated online environments, by explicitly fostering attitudes and behaviours that not only demonstrate a successful approach to academic integrity, but provide the knowledge and skills needed by educators from a wide range of professional education sectors/positions.

\footnotetext{
Authors' information

Judy O'Connell is senior lecturer and Quality Learning and Teaching Academic Lead (Online) in the Faculty of Science Charles Sturt University. As a Courses Director in the Faculty of Education her work has been recognised by two awards for Academic Excellence and Leadership. Her professional leadership spans school and tertiary education, with a focus on libraries, learning spaces, online learning design, innovation, social media and technology for learning and teaching. She has also been a member of the NMC K-12 Horizon Report Advisory Board since 2009, and likes to stay in touch with emerging technologies, particularly in relation to learning experiences. Judy writes online at http://judyoconnell.com.
}

\section{Competing interests}

The author declares that there are no competing interests.

Received: 17 May 2016 Accepted: 5 September 2016

Published online: 07 November 2016

\section{References}

Ally M (2004) Foundations of educational theory for online learning. In: Anderson T, Elloumi F (eds) Theory and practice of online learning. Creative Commons Athabasca University, Athabasca

Anderson T, Dron J (2011) Three generations of distance education pedagogy. Int Rev Res Open Distrib Learn 12(3):8097. Retrieved from http://www.irrodl.org/index.php/irrodl/article/view/890.

Baggio B, Beldarrain Y (2011) Academic integrity: ethics and morality in the 21st century. In: Anonymity and Learning in digitally mediated communications: authenticity and trust in cyber education. Hershey, p 131-154. doi: 10.4018/ 978-1-60960-543-8.ch007

Bawden D, Robinson L (2012) Introduction to information science. Facet, London

Beetham H, Sharpe R (eds) (2013) Rethinking pedagogy for a digital age: designing for 21st century learning. Routledge, New York

Biggs J, Tang C (2011) Teaching for quality learning at university. Open University press, London

Boling EC, Hough M, Krinsky H, Saleem H, Stevens M (2012) Cutting the distance in distance education: perspectives on what promotes positive, online learning experiences. Internet High Educ 15(2):118-126, http://doi.org/10.1016/j. iheduc.2011.11.006

Brown JS (1999) Learning, working, and playing in the digital age. Serendip. Retrieved on February 12, 2015 from http://serendip.brynmawr.edu/sci_edu/seelybrown/seelybrown.html

Cho YH, Choi H, Shin J, Yu HC, Kim YK, Kim JY (2015) Review of research on online learning environments in higher education. Procedia Soc Behav Sci 191:2012-2017, http://doi.org/10.1016/j.sbspro.2015.04.634

Council, AQF (2013) Australian qualifications framework

Desai MS, Hart J, Richards TC (2008) E-Learning: paradigm shift in education. Education 129(2):327-334

Franklin T, Van Harmelen M et al (2007) Web 2.0 for content for learning and teaching in higher education., Retrieved from https://staff.blog.ui.ac.id/harrybs/files/2008/10/web-2-for-content-for-learning-and-teaching-in-highereducation.pdf

Garrison DR, Anderson T, Archer W (1999) Critical inquiry in a text-based environment: computer conferencing in higher education. Internet High Educ 2(2):87-105

Haste H (2009) What is 'competence' and how should education incorporate new technology's tools to generate 'competent civic agents'. Curric J 20(3):207-223. doi:10.1080/09585170903195845

Haythornthwaite C, Andrews R (2011) E-learning theory and practice. Thousand Oaks Sage Publications, California

Hulsart R, McCarthy V (2011) Utilizing a culture of trust to promote academic integrity. J Contin High Educ 59(2):92-96. doi:10.1080/07377363.2011.568827

Kim KJ, Bonk CJ (2006) The future of online teaching and learning in higher education: The Survey Says.... Educause Quarterly 29(4):22-23

Lang C, Lemon N (2014) Embracing social media to advance knowledge creation and transfer in the modernized university: management of the space, the tool, and the message. In: Fitzgerald T (ed) Advancing knowledge in 
higher education., pp 112-131, IGl Global, Retrieved from http://www.igi-global.com.ezproxy.csu.edu.au/gateway/ chapter/full-text-html/113512

Lee MJ, McLoughlin C, Chan A (2008) Talk the talk: learner-generated podcasts as catalysts for knowledge creation. Br J Educ Technol 39(3):501-521

Li Y (2007) Apprentice scholarly writing in a community of practice: an interview of an NNES graduate student writing a research article. TESOL Q 41(1):55-79, http://doi.org/10.2307/40264331

Lieberman A, Mace DP (2009) Making practice public: teacher learning in the 21st century. J Teach Educ 61(1-2):77-88. Lievrouw LA (2011) Alternative and activist new media. Polity Press, Cambridge

Löfström E, Trotman T, Furnari M, Shephard S (2015) Who teaches academic integrity and how do they teach it? High Educ 69(3):435-448. doi:10.1007/s10734-014-9784-3

Macfarlane B, Zhang J, Pun A (2014) Academic integrity: a review of the literature. Stud High Educ 39(2):339-358 doi:10.1080/03075079.2012.709495

McLoughlin C, Lee M J (2011) Pedagogy 2.0: Critical challenges and responses to web 2.0 and social software in tertiary teaching. In: M Lee C McLoughlin (ed) Web 2.0-Based E-Learning: Applying Social Informatics for Tertiary Teaching Hershey, p 43-69. doi: 10.4018/978-1-60566-294-7.ch003

O'Connell J (2014) A multidisciplinary focus on 21st century digital learning environments: new program at CSU. In: Hegarty B, McDonald J, Loke S-K (eds) Rhetoric and reality: critical perspectives on educational technology, Proceedings ASCILITE Dunedin., pp 201-210

Prescott L (2016) Using collaboration to foster academic integrity. Open Learn 31(2):152-162. doi:10.1080/02680513. 2016.1169162

Rienties B, Kinchin I (2014) Understanding (in)formal learning in an academic development programme: A social network perspective. Teach Teach Educ 39:123-135

Romiszowski A, Mason R (2004) Computer-mediated communication. In: Jonassen DH (ed) Handbook of research for educational communications and technology p 397-431. Lawrence Erlbaum Associates, Mahwah

Scardamalia M, Bransford, Kozma B, Quellmalz E (2012) New assessments and environments for knowledge building. In: Assessment and teaching of 21st century skills. Springer, Netherlands, pp 231-300

Shea P, Bidjerano T (2010) Learning presence: towards a theory of self-efficacy, self-regulation, and the development of a communities of inquiry in online and blended learning environments. Comput Educ 55(4):1721-1731

Siragusa L, Dixon KC, Dixon R (2007) Designing quality e-learning environments in higher education, Proceedings ASCILITE., Retrieved from http://www.ascilite.org/conferences/singapore07/procs/siragusa.pdf

Sutherland-Smith W (2008) Plagiarism, the Internet, and student learning: Improving academic integrity. Routlege, London

Thomas D, Brown JS (2011) A new culture of learning: cultivating the imagination for a world of constant change (219). Createspace, Lexington

Thompson M (2007) From distance education to e-learning. In: Haythornthwaite RAC (ed) The SAGE handbook of Elearning research. SAGE Publications, London, pp 159-179

Turner J, Reid M, Shahabudin K (2011) Reflective thinking. In practice-based learning 1. Study Advice and Math Support, University of Reading, Reading

Turner SP, Beemsterboer PL (2003) Enhancing academic integrity: formulating effective honor codes. J Dent Educ 67(10):1122-1129

York-Barr J, Sommers WA, Ghere GS, Montie J (2006) Reflective practice to improve schools: an action guide for educators, 2nd edn. Corwin, Thousand Oaks

Zheng RZ, Dahl LB (2010) An ontological approach to online instructional design. In: H Song T Kidd (eds) Handbook of research on human performance and instructional technology. IGI Global, p 1-23. doi: 10.4018/978-1-60566-782-9.ch001 